\title{
Neuron specific enolase in asphyxiated newborns: association with encephalopathy and cerebral function monitor trace
}

\author{
E Thornberg, K Thiringer, H Hagberg, I Kjellmer
}

\begin{abstract}
Neuron specific enolase (NSE) in serum and cerebrospinal fluid (CSF) and glutamate in CSF were investigated in the immediate postasphyctic period in 22 term newborn infants. The cerebral function monitor (CFM) pattern was also assessed and hypoxic-ischaemic encephalopathy (HIE) was graded. NSE was significantly increased in the CSF of infants with HIE (median value $25.4 \mu \mathrm{g} / \mathrm{l}$ ) compared with control infants $(10 \cdot 0 \mu \mathrm{g} / \mathrm{l})$. Infants with the highest concentrations died.

NSE in CSF correlated with the degree of asphyxial damage. Glutamate and NSE in CSF did not correlate, presumably due to the different time factors of the release after the insult. NSE in CSF corresponded well with the type of CFM pattern, which was also highly predictive of outcome. (Arch Dis Child 1995; 72: F39-F42)
\end{abstract}

Keywords: neuron specific enolase, cerebral function, asphyxia neonatorum, hypoxic-ischaemic encephalopathy.

Prediction of outcome after perinatal asphyxia is important and difficult. Grading of hypoxicischaemic encephalopathy (HIE) ${ }^{12}$ is a better predictor than thin Apgar score. ${ }^{3}$ Neurophysiological measurements have been investigated as predictors of outcome and seem very promising. ${ }^{4-8}$

Enzymes, such as lactate dehydrogenase ${ }^{9}$ and brain specific creatine kinase, ${ }^{10}$ have been advocated as predictors of outcome after brain lesions. Enolase, a glycolytic enzyme, has recently been reported as a biochemical index of neuronal damage. ${ }^{11-14}$ Enolase (EC 4.2.1.11) has five isoenzymes. Those containing the gamma subunit, predominantly found in neurons of the central and peripheral nervous system, are called neuron-specific enolase (NSE). The specificity of NSE has been discussed as it is also present in erythrocytes, thrombocytes, and neuroendocrine cells. ${ }^{15}$ NSE is released into both CSF and serum after damage to the central nervous system. ${ }^{13}$ Increased concentrations also occur after cardiac arrest in adults, when the concentration in CSF correlates with neurological outcome. ${ }^{16}$

Glutamate, one of the excitatory amino acids, has recently been reported as being present in the CSF of asphyxiated newborns and its level has been shown to correlate with grade of HIE and outcome. ${ }^{17} 18$
The cerebral function monitor (CFM), a simplified single channel electroencephalogram (EEG) monitor with an amplitude distribution of the EEG signal, has been used in term neonates to evaluate prognosis after perinatal asphyxia. The different patterns after asphyxia and their clinical implications for prediction of prognosis have been described before. ${ }^{6-8} \mathrm{~A}$ continuous CFM pattern in the first few days of life indicates a good outcome; a consistent burst-suppression or paroxysmal pattern is associated with a poor outcome. The aim of this study was to evaluate the concentrations of NSE in CSF and serum as a marker of the severity of perinatal asphyxia in term neonates and to elucidate the relation between the concentrations of NSE and glutamate in CSF, and the CFM pattern, and grade of HIE in relation to outcome.

\section{Methods}

All infants were treated at the neonatal unit at Sahlgrenska Hospital, and the neonatal or paediatric intensive care units at Östra Hospital, Göteborg. Twenty two term infants (gestational age of $>37$ weeks) with perinatal asphyxia, defined as an Apgar score of $<5$ at five minutes or a requirement for positive pressure ventilation for more than three minutes, or both, were included. Fifteen of the infants were treated in the intensive care unit with positive pressure ventilation. Ten of these infants were also part of a previous study on CFM and prediction of outcome. ${ }^{8}$ The control group consisted of nine neurologically normal term infants subjected to lumbar puncture for suspected infection. All turned out to have normal CSF values for leucocytes, protein, and cultures.

The 22 asphyxiated infants were classified as having mild $(n=9)$, moderate $(n=8)$, or severe $(n=5)$ HIE according to clinical criteria. ${ }^{1}$

\section{CSF OR BLOOD SAMPLING AND ANALYSIS}

Samples from CSF for NSE and glutamate analysis were taken between two and 32 hours after birth except in one case (96 hours). In three infants repeated samples were taken. The first value obtained was used for statistical calculations. Samples from control infants were all taken within the first three days of life. Serum samples of NSE were taken two to 64 hours after birth. All samples were immediately frozen $\left(-80^{\circ} \mathrm{C}\right)$. Haemolytic serum samples were discarded, as falsely high NSE 
Table 1 Birth weight (mean (SD)), Apgar score (mean, range), and number of infants in control and study groups

\begin{tabular}{|c|c|c|c|c|c|c|c|}
\hline & \multirow{2}{*}{$\begin{array}{l}\text { Birth weight } \\
(g)\end{array}$} & \multicolumn{2}{|l|}{ Apgar score } & \multicolumn{2}{|c|}{$N S E(n=)$} & \multirow{2}{*}{$\begin{array}{l}\text { Glutamate } \\
(n=)\end{array}$} & \multirow{2}{*}{$\begin{array}{l}C F M \\
(n=)\end{array}$} \\
\hline & & 5 Minutes & 10 Minutes & $C S F$ & Serum & & \\
\hline $\begin{array}{l}\text { Control }(n=9) \\
\text { HIE mild }(n=9) \\
\text { HIE moderate }(n=8) \\
\text { HIE severe }(n=5) \\
\text { Total }\end{array}$ & $\begin{array}{l}3550(695) \\
3670(683) \\
3528(559) \\
3630(670)\end{array}$ & $\begin{array}{l}9 \cdot 7(7-10) \\
3 \cdot 0(1-6) \\
2 \cdot 9(1-5) \\
1 \cdot 6(0-3)\end{array}$ & $\begin{array}{l}10(9-10) \\
5 \cdot 0(1-7) \\
4 \cdot 6(2-8) \\
2 \cdot 4(0-4)\end{array}$ & $\begin{array}{r}9 \\
8 \\
8 \\
4 \\
29\end{array}$ & $\begin{array}{r}7 \\
3 \\
5 \\
15\end{array}$ & $\begin{array}{r}6 \\
5 \\
5 \\
16\end{array}$ & $\begin{array}{r}9 \\
6 \\
5 \\
20\end{array}$ \\
\hline
\end{tabular}

HIE=hypoxic-ischaemic encephalopathy; NSE=neuron-specific enolase;

$\mathrm{CSF}=$ cerebrospinal fluid; $\mathrm{CFM}=$ cerebral function monitoring.

concentrations might be obtained. The mean red cell count in the CSF of the asphyxiated infants was 7539 cells/1 (range 0-64 000). There was no significant correlation between red cell count and concentrations of NSE. NSE was determined using the NSE radioimmunoassay kit introduced by Pharmacia in 1985. Calibration against pure NSE, prepared according to the method of Pålman, 19 was carried out at each series of measurements. The method measures concentrations in the range $2-200 \mu \mathrm{g} / 1$; the detection limit is less than $2 \mu \mathrm{g} / \mathrm{l}$. Glutamate was determined with high performance liquid chromatography after derivatisation, as described earlier. ${ }^{1820}$

\section{CEREBRAL FUNCTION MONITORING}

CFM, a simplified single channel EEG monitor (Lectromed Ltd, Jersey), as well as its variant the CFAM monitor (Health Care Developments Ltd, UK), have been well described. ${ }^{21}$ The technical details of CFM recording after perinatal asphyxia have also been given before. ${ }^{8}$ The different CFM patterns in the postasphyctic period were classified as continuous, paroxysmal, or burstsuppression. CFM was intermittently recorded during the first three days of life and the predominant pattern during the second half of the second day of life was used.

Because all investigations (NSE, glutamate, CFM) were not complete in all infants, the number of infants investigated in each HIE group is shown in table 1 , together with birth weight and Apgar score at five and 10 minutes. All infants in the study group were followed up prospectively by a paediatrician or paediatric neurologist. Follow up time is 18 months unless indicated. The study was approved by the Ethics Committee for Medical Research at the University of Göteborg.

\section{STATISTICAL METHODS}

Because of the small number of patients and the skewed distribution of most variables, nonparametric statistics were used. The Wilcoxon rank sum test was used for comparison of NSE values between the control group and the study group. The Kruskall Wallis one way analysis of variance was used to compare the three groups for different grades of HIE. This test was supplemented by the Wilcoxon rank sum test when comparing two groups. Spearman's rank correlation coefficient was used to determine the correlation between CSF red blood

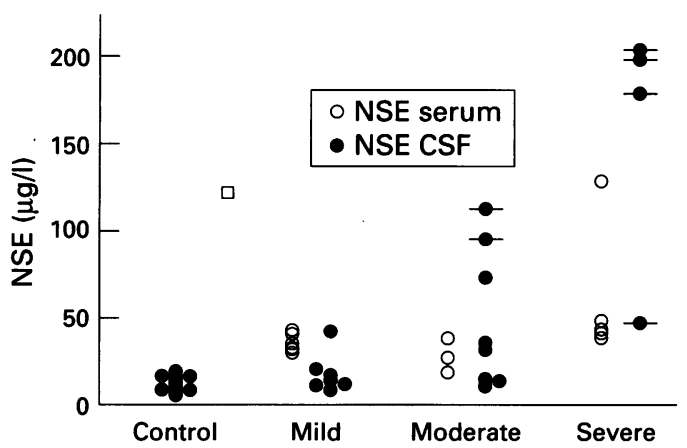

Figure 1 NSE concentration in CSF and serum of control infants and asphyxiated infants with mild, moderate, and severe HIE. Dots marked with a horizontal bar represent infants who died or developed severe neurological damage.

cell count and NSE values. Concentrations of NSE were expressed as median values and (range).

\section{Results}

The NSE concentration of CSF in infants with HIE varied widely, the median (range) value being $25.4(9-200) \mu \mathrm{g} / \mathrm{l}$. This was significantly different from the median value in control infants: $10.0(5 \cdot 7-20) \mu \mathrm{g} / \mathrm{l} ;(\mathrm{p}<0.001)$. The NSE concentration was significantly higher in infants with severe HIE (185 (49-200) $\mu \mathrm{g} / \mathrm{l})$ compared with moderate $(34.5(12-114) \mu \mathrm{g} / \mathrm{l})$ $(\mathrm{p}<0.05)$ or mild $(17.2(9-43) \mu \mathrm{g} / \mathrm{l})$ HIE $(\mathrm{p}<0.01)$.

Figure 1 shows the concentrations of NSE, in serum and CSF, for each individual infant. Three infants with moderate HIE (NSE CSF concentrations of 12,37 , and $74 \mu \mathrm{g} / \mathrm{l}$ ) have so far been followed up at 5, 7, and 10 months of age, respectively, and were normal. In those infants in whom serum and CSF values were obtained simultaneously $(n=10)$ the serum values roughly doubled the CSF values in infants with mild and moderate HIE, while in severe HIE, CSF values were more than double the serum values, with one exception (fig 2).

Figure 3 shows the relation between NSE concentrations in CSF with time of sampling. One infant with moderate HIE and extensive ischaemic changes seen on computed brain tomograms had a high concentration of NSE $(96 \mu \mathrm{g} / \mathrm{l})$ on the fourth day of life.

Figure 4 shows the lack of correlation between glutamate and NSE values in CSF. Table 2 shows the CFM patterns in relation to grade of HIE, NSE in CSF, and outcome.

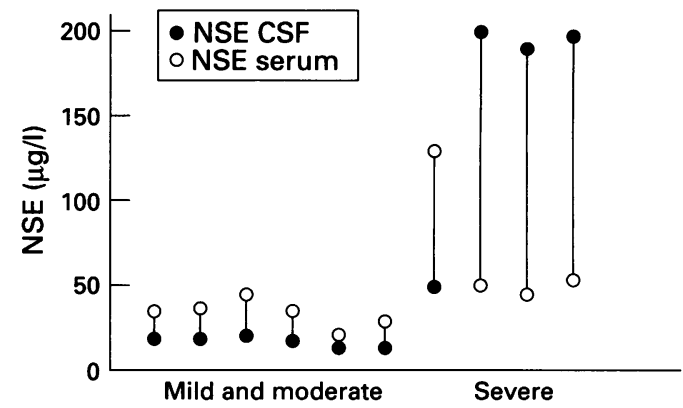

Figure 2 Simultaneously recorded concentrations of NSE in CSF and serum in infants with mild to moderate and severe HIE. 


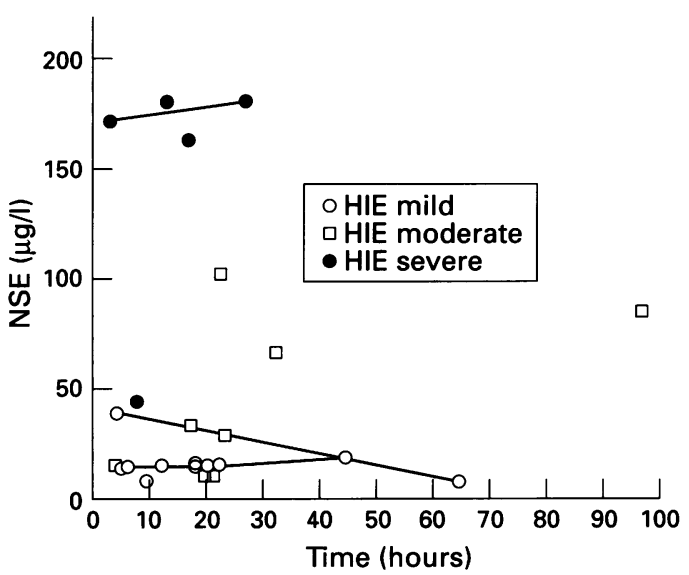

Figure 3 Concentration of NSE in CSF and sampling time in each individual infant $(n=20)$. The lines connect values from the same patient.

CFM recordings from the second day of life were obtained in 20 of 22 infants. The two infants not recorded had moderate HIE and greatly increased concentrations of NSE in CSF (96 and $74 \mu \mathrm{g} / \mathrm{l}$, respectively) and computed tomography of the brain showed signs of parenchymal damage. One of them showed a severe neurodevelopmental disturbance at 6 months of age, the other one was doing well at 10 months of age. Continuous CFM pattern was present in 14 infants, all having mild or moderate HIE. Ten of these infants were considered normal at 18 months of age. One infant rapidly recovered from the asphyxia but died at 2 months of age from sudden infant death syndrome (SIDS). A brain necropsy was normal. One infant with mild HIE and a value of $9 \mu \mathrm{g} / 1$ of NSE in CSF developed a mild right-sided hemiplegia. The remaining two infants were, as stated above, doing well at 5 and 7 months of age. All six infants with burst-suppression or paroxysmal patterns either died or developed persistent neurological damage.

\section{Discussion}

Clinical grading of HIE, which has been proposed as a highly sensitive method of predicting death or severe handicap ${ }^{2}$ after

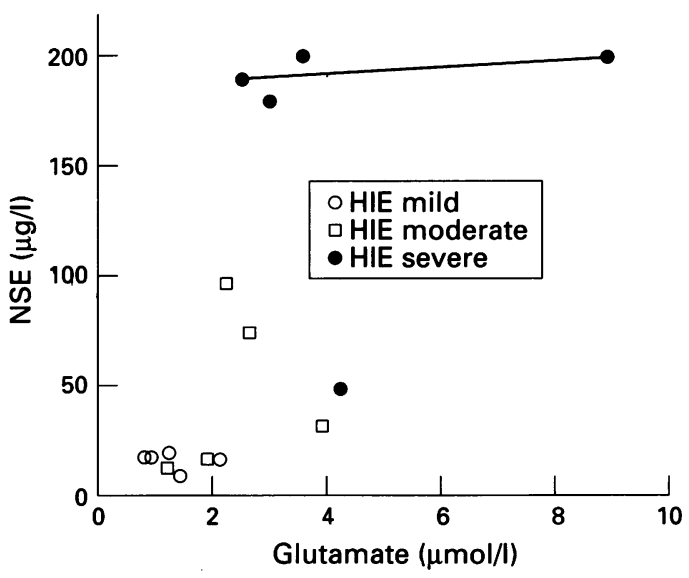

Figure 4 NSE and glutamate values in CSF in individual infants with different grades of HIE. The horizontal line connects values from the same patient. perinatal asphyxia, has its limitations. Therapeutic interventions will probably change or modify the clinical signs, thus making the grading of HIE difficult and unreliable. In our study two thirds of the infants were on controlled ventilation and staging was influenced by sedatives, hypnotics, and, occasionally, muscle relaxants which may have prevented clinical seizures and made the infants more lethargic, with secondary effects on reflex activity.

Prediction of prognosis seems to be adequate with regard to infants with mild HIE (almost all infants have a favourable outcome) and infants with severe HIE (most have a dismal outcome), but the prognostic impact of moderate HIE is unclear. Infants with moderate HIE have a varied outcome and it is within this group that most efforts must be made to predict prognosis.

In this study values of NSE in CSF correlated with grade of HIE, but there was no clear association between NSE and glutamate (fig 4). Glutamate has been shown to correlate with grade of HIE. ${ }^{18}$ However, the time course of glutamate release may be very different from that of NSE. This is illustrated by the case in which the first CSF sample, taken at two hours, showed a very high NSE value but a low glutamate concentration (fig 4). When sampling was repeated at 26 hours, the NSE concentration was still maximally increased, but by then the glutamate was also high.

In neurological recovery after cardiac arrest in adults the CSF NSE value at 76 hours after resuscitation was most indicative of prognosis compared with values at four and 28 hours. ${ }^{16}$ In other studies in adults NSE increased 18 hours to four days after cerebral infarction, ${ }^{13}$ and during the first days following anoxaemia. ${ }^{14}$ The optimal time for prognosis in newborn infants after perinatal asphyxia remains uncertain. Figure 3 indicates that there are only minor changes with time over the first 48 hours. As delayed neuronal death peaks between the second and third day of life, the optimal time is most likely to be at around 72 hours.

The cause and timing of cerebral damage in infants with perinatal asphyxia has been a matter of discussion. ${ }^{22}$ In our study all neonates except one who either died or turned

Table 2 CFM pattern in relation to HIE, concentration of $N S E^{\star}$ in $C S F$, and outcome

\begin{tabular}{lll}
\hline & $\begin{array}{l}\text { CFM continuous } \\
\text { pattern }(n=14)\end{array}$ & $\begin{array}{l}\text { CFM burst-suppression } \\
\text { or paroxysmal pattern } \\
(n=6)\end{array}$ \\
\hline HIE & & \\
Mild & 9 & 0 \\
Moderate & 5 & 1 \\
Severe & 0 & 5 \\
NSE (median (range) & & $180(49-200)$ \\
$\quad \mu g / 1)$ & $17(9-43)$ & 0 \\
Outcome & $10 / 14 \dagger$ & 2 \\
Normal & 0 & 4 \\
Severe damage & 0 &
\end{tabular}

^NSE values were obtained from 13 and five infants, respectively, in each CFM group.

†Two infants are excluded due to short follow up. One infant died of SIDS at 6 weeks of age, but was considered normal at that time. One infant has a mild right-sided hemiplegia but is mentally normal at the time of writing. 
out to have permanent brain injury also had substantially increased NSE concentrations in the CSF (fig 1). NSE is a documented marker of ongoing neuronal damage, and this suggests that the damage occurred in the perinatal period. One infant with mild HIE and a normal concentration of NSE in CSF $(9 \mu \mathrm{g} / \mathrm{l})$ developed right-sided hemiplegia. This is not considered a typical sequela of perinatal asphyxia and the lack of an increase in NSE in the CSF may support the suggestion that this case of hemiplegia had an antenatal origin.

The raised CSF values, compared with serum values in severe HIE, indicate that the NSE in CSF originated from neuronal damage and was not a reflection of increased concentration in the blood. A study on the concentration of NSE in plasma in cases of adult cardiac arrest showed that six out of 14 resuscitated patients who eventually died from neurological sequelae failed to show increased NSE concentrations in plasma. ${ }^{23}$ If peripheral cells were the main source of NSE these patients would also have had raised NSE values. In this study the median CSF NSE value in the control group was $10.0 \mu \mathrm{g} / 1$ which is very similar to the normal value in adults $(11 \mu \mathrm{g} / \mathrm{l}) .{ }^{15}$ Infants with mild HIE generally had low CSF values, all except one below $20 \mu \mathrm{g} / \mathrm{l}$, and they all showed a continuous CFM pattern.

Infants with moderate HIE had a greater variation in NSE values which might reflect the variations in brain damage and outcome in this group. The two infants with the highest values (96 and $114 \mu \mathrm{g} / \mathrm{l}$ ) have severe neurodevelopmental disturbances. So far all infants with moderate HIE who had a continuous CFM pattern have had a normal outcome. With one exception all infants with severe HIE had extremely high NSE values and CFM patterns, indicating a poor outcome. Half of the infants recorded with CFM have been reported before. ${ }^{8}$ Even so, this study corroborates our previous results that CFM is a very useful tool for the prediction of outcome after perinatal asphyxia.

Financial support was obtained from the Swedish Medical Research Council project 2591, 9455, the Faculty of Medicine, Göteborg University, Sven Jerring foundation, The 1987 Foundation for stroke research, Åke Wiberg foundation, Åhlé foundation, $M$ Bergwall foundation, First of May Flowe Annual Campaign and the Laerdal Foundation for Acute Medicine.

1 Sarnat HB, Sarnat MS. Neonatal encephalopathy following fetal distress. A clinical and electroencephalographic study. Arch Neurol 1976; 33: 696-705.
2 Levene MI, Sands C, Grindulis H, Moore JR. Comparison of two methods of predicting outcome in perinatal asphyxia. Lancet 1986; i: $67-9$.

3 Nelson KB, Ellenberg JK. Apgar scores as predictors of chronic neurological disability. Pediatrics 1981; 68: 36-44.

4 Holmes G, Rowe J, Hafford J, Schmidt R, Testa M, Zimmerman A. Prognostic value of the electroencephaNeurophysiol 1982; 53: 60-72.

5 DeVries LS, Pierrat V, Eken P, Minami T, Daniels H, Casaer P. Prognostic value of early somatosensory evoked potentials for adverse outcome in full-term infants with birth asphyxia. Brain Dev 1991; 13: 320-5.

6 Bjerre I, Hellström-Westas L, Rosén I, Svenningsen NW. Monitoring cerebral function after severe asphyxia in infancy. Arch Dis Child 1983; 58: 997-1002.

7 Hellstöm-Westas L, Rosén I, Svenningsen NW. The prognostic value of early CFM tracings after severe birth asphyxia in full-term infants: A retrospective analysis. Biol Neonate 1992; 62: 306 .

8 Thornberg E, Ekström-Jodal B. Cerebral function monitoring: a method of predicting outcome in term neonates after severe perinatal asphyxia. Acta Paediatr 1994; 83: 596-601

9 Fernandez F, Quero J, Verdú A, Ferreiros MC, Daimiel E, Roche MC. LDH isoenzymes in CSF in the diagnosis of neonatal brain damage. Acta Neurol Scand 1986; 74: 30-3.

10 DePraeter C, Vanhaesebrouck P, Govaert P, Delanghe J, Leroy J. Creatine kinase isoenzyme BB concentrations in the cerebrospinal fluid of newborns: relationship to short term outcome. Pediatrics 1991; 88: 1204-10.

11 Steinberg R, Gueniau C, Scarna H, Keller A, Worcel M, Pujol JF. Experimental brain ischemia: Neuron-specific enolase level in cerebrospinal fluid as an index of neuronal damage. F Neurochem 1984; 43: 19-24.

12 Hårdemark HG, Persson L Bolander H, Hillered L, Olsson $\mathrm{Y}$, Påhlman S. Neuron-specific enolase is a marker of cerebral ischemia and infarct size in rat cerebrospinal cerebral ischemia and infarct
fluid. Stroke 1988; 19: 1140-4.

13 Persson L, Hårdemark HG, Gustafsson J, Rundström G, Mendel-Hartvig I, Esscher T, et al. S-100 protein and neuron-specific enolase on cerebrospinal fluid and serum: Markers of cell damage in human central nervous system. Stroke 1987; 18: 911-7.

14 Scarna H, Delafosse B, Steinberg R, Debilly G, Mandrand B, Keller A, et al. Neuron-specific enolase as a marker of neuronal lesions during various comas in man. Neurochem Int 1982; 4: 405-11.

15 Brown K, Kynoch P, Thompson R. Immunoreactive nervous system specific enolase (14-3-2 protein) in nervous system specific enolase (14-3-2 protein) in 1980; 101: 257-64.

16 Kärkelä J, Bock E, Kaukinen S. CSF and serum brainspecific creatine kinase isoenzyme (CK-BB), neuronspecific enolase (NSE) and neural cell adhesion molecule NCAM) as prognostic markers for hypoxic brain injury after cardiac arrest in man. $\mathcal{F}$ Neurol Sci 1993; 116: 100-9.

17 Riikonen R, Kero P, Simell O. Excitatory amino acids in cerebrospinal fluid in neonatal asphyxia. Pediatr Neurol 1992; 8: $37-40$.

18 Hagberg $\mathrm{H}$, Thornberg $\mathrm{E}$, Blennow $M$, Kjellmer I, Lagercrantz $\mathrm{H}$, Thiringer $\mathrm{K}$, et al. Excitatory amino acids in the cerebrospinal fluid of asphyxiated infants: relationship to hypoxic-ischemic encephalopathy. Acta Paediatr ship to hypoxic-isch

19 Påhlman S, Esscher T, Bergvall P, Odelstad L. Purification and characterization of human neuron-specific enolase: radioimmunoassay development. Tumour Biol 1984; 5: 127-39.

20 Lindroth P, Hamberger A, Sandberg M. Liquid chromatographic determination of amino acids after precolumn fluorescence derivatization. Neuromethods 1985; 3: 97-116.

21 Prior PF, Maynard DE, eds. Technical and practical aspects of monitoring. In: Monitoring cerebral function: long term monitoring of EEG and evoked potentials. 2nd edn. Amsterdam: Elsevier, 1986: 85-140.

22 Nelson KB, Leviton A. How much of neonatal encephalopathy is due to birth asphyxia? Arch Dis Child 1991; 145: pathy is due $1325-31$.

23 Dauberschmidt R, Zinsmeyer J, Mrochen H, Meyer M. Changes of neuron-specific concentration in plasma after cardiac arrest and resuscitation. Mol Chem Neuropathol $1991 ; 14: 237-45$. 